\title{
Práticas De Autoconhecimento No Currículo Das Escolas Não- Tradicionais - O Exercício Do (Re)Conhecer-Se
}

\author{
Prácticas De Autoconocimiento En El Currículo De Las Escuelas No
}

Tradicionales - El Ejercicio Del (Re) Conocer

Practices Of Self-Knowledge In Non-Traditional School Curriculum - The

\author{
(Re) Knowing Exercise
}

\author{
Juliana Artigas Flores ${ }^{1}$ \\ Lavínia Schwantes ${ }^{2}$ \\ Caroline da Cunha Rezende Silva ${ }^{3}$
}

\begin{abstract}
Resumo
Este trabalho foi elaborado a partir da análise de quatro vídeos que apresentam a rotina escolar das Escolas não tradicionais (ENT). Através dos vídeos, as autoras extraíram as falas mais pertinentes dos documentários, organizando assim em quadros os trechos dos vídeos que nos permitiram compreender de forma mais ampla como o currículo das ENT trabalham o autoconhecimento. Na elaboração do artigo tivemos como resultados quatro amplas categorias nas quais foi possível observar algumas das ferramentas utilizadas pelas ENT para incentivar o exercício do conhecer-se entre os sujeitos da comunidade escolar. Por fim, observamos através das falas dos sujeitos como a subjetividade vai sendo construída através da utilização de diferentes ferramentas, as quais se intercalam entre si durante esse processo. Concluímos também que, as ENT apresentam como eixo norteador de suas práticas o autoconhecimento, utilizando a psicologia, a área da saúde e demais áreas terapêuticas como gatilhos para proporcionar nos sujeitos um ambiente escolar emocionalmente mais confortável e equilibrado, prezando também por valores mais coletivos dentro de suas práticas.
\end{abstract}

Palavras-Chave: Autoconhecimento; Currículo; Educação Emocional; Educação Integral; Escolas Não Tradicionais.

\section{Resumen}

Este trabajo fue elaborado a partir del análisis de cuatro videos que presentan la rutina escolar de las Escuelas no tradicionales (ENT). A través de los vídeos, las autoras extrajeron las palabras más pertinentes de los documentales, organizando así en cuadros los fragmentos de los videos que nos permitieron comprender de forma más amplia como el currículo de las ENT trabajan el autoconocimiento. En la elaboración del artículo tuvimos como resultados cuatro amplias categorías en las cuales fue posible observar algunas de las herramientas utilizadas por las ENT para incentivar el ejercicio del conocimiento entre los sujetos de la comunidad escolar. Por último, observamos a través de las palabras de los sujetos como la subjetividad va siendo construida a través de la utilización de diferentes herramientas, las cuales se intercalan entre sí durante

\footnotetext{
${ }^{1}$ Graduada em Ciências Biológicas Licenciatura e Bacharelado (FURG). Mestranda do Programa de PósGraduação em Educação em Ciências: Química da Vida e Saúde na Universidade Federal do Rio Grande (FURG); Rio Grande, RS/Brasil; juliana_artigas@ @otmail.com

${ }^{2}$ Doutora em Educação em Ciências pela Universidade Federal do Rio Grande. Professora adjunta da Universidade Federal do Rio Grande (FURG) no curso de Licenciatura em Ciências Biológicas e coordenadora do Programa de Pós-Graduação em Educação em Ciências (PPGEC/FURG); ); Rio Grande, RS/Brasil; laviniasch@gmail.com

3 Graduanda no Curso de Ciências Biológicas Licenciatura (FURG); Rio Grande, RS/Brasil; carol.rj14@hotmail.com
} 
ese proceso. Concluimos también que las ENT presentan como eje orientador de sus prácticas el autoconocimiento, utilizando la psicología, el área de la salud y demás áreas terapéuticas como gatillos para proporcionar en los sujetos un ambiente escolar emocionalmente más cómodo y equilibrado, prezando también por valores más colectivos dentro de sus prácticas.

Palabras claves: Autoconocimiento; Currículo; Educación Emocional; Educación Integral; Escuelas No Tradicionales.

\begin{abstract}
This work was elaborated from the analysis of four videos that present the school routine of non-traditional schools (ENT). Through the videos, the authors extracted the most pertinent statements from documentaries, thus organizing in tabs the excerpts from the videos that allowed us to understand in a broader way how the ENT curriculum works self-knowledge. In the elaboration of the article we had as results four broad categories in which it was possible to observe some of the tools used by ENTs to encourage the exercise of knowing oneself among the subjects of the school community. Finally, we observe through the speeches of the subjects how subjectivity is being constructed through the use of different tools, which intercalate with each other during this process. We also conclude that, as a guideline for ENT, self - knowledge, using psychology, health and other therapeutic areas as triggers to provide the subjects with an emotionally more comfortable and balanced school environment, of their practices.
\end{abstract}

Keywords: Curriculum; Emotional Education; Integral Education; Non-Traditional School; Self-knowledge.

\title{
1. Introdução
}

As Escolas Não-Tradicionais (ENT) vêm marcando presença, cada vez mais, em espaços midiáticos e sociais. Hoje, com uma maior possibilidade de ferramentas, tais como: facebook, youtube, instagram, medium e outros, as ENT parecem ter maior força, assim como, um público mais interessado em conhecer, estudar e também construir novos ideias a cerca da educação. O trabalho aqui presente deriva da pesquisa de mestrado da primeira autora, cuja temática central é analisar o movimento das ENT através de documentários. Assim, trazemos aqui um recorte sobre a esta temática, explorando, neste trabalho, como essas escolas trabalham a questão do autoconhecimento em seus currículos.

A centralidade deste trabalho é compreender como o currículo das ENT inclui em sua rotina escolar certas práticas de autoconhecimento, tais como: meditação, exercícios de escuta ativa, práticas de roda/cirandas e assembléias estudantis. Também analisar como estas práticas do cuidar de si podem auxiliar nos demais processos educativos dos sujeitos (ex: aprender matemática), tanto dos/das professores/professoras como dos/das alunos/alunas. Dessa forma, para a realização deste estudo, utilizamos como material empírico documentários gravados em três ENT, utilizando as falas de alunos e da comunidade escolar, como corpus de análise.

Para elaborarmos nosso trabalho, nos debruçamos, primeiramente, nos estudos de currículo de Silva (2015) e Paraíso $(2009 ; 2015)$ para explorarmos a compreensão acerca do que entende-se por currículo. Assim, sucintamente, apontamos que o currículo escolar não limita-se ao artefato em si, ao documento impresso esquecido na gaveta da escola. Mas sim, a 
toda a forma de produção de saberes que ocorre dentro do espaço escolar. Assim como, as relações de poder que circulam por entre os sujeitos e também, porque não, por e entre os ambientes. O currículo da escola extrapola os conteúdos e/ou a práticas pedagógicas realizadas nesse espaço. Ele explora, como diria Foucault (2014) o dito e o não dito dentro do espaço escolar. Dos olhares até as falas. Dos cartazes ao silêncio. Daquilo que não pode ser escrito, nem dito. Tudo que ocorre dentro do ambiente escolar, faz parte, elabora, dinamiza e modifica o currículo escolar diariamente.

Já para falarmos acerca das ENT pontuamos outros estudos já realizados pelas primeiras autoras (2017a; 2017b) e o de Barrera (2016). Dessa forma, compreendemos que as ENT são um movimento de renovação no âmbito da educação, não somente a nível brasileiro, mas também a nível mundial (REEVO, 2016). Olhando para a educação numa perspectiva histórica, notamos que Künzle (2011) disserta em seu trabalho sobre como algumas escolas, entre os anos de 1960 e 1970, que tentaram romper com o modelo tradicional de educação da época. Dessa forma, a autora aponta que esse movimento de "educação alternativa" já ocorria de forma disseminada no Brasil, tendo como raiz teórica as pedagogias: Ativas, Socialista e a Libertária. O trabalho de Künzle (2011) aponta isso principalmente na cidade de Curitiba. Já Tamberlini (2016) complementa essa informação sobre possíveis ENT no período préditadura através das escolas denominadas como Ginásios Vocacionais ou Ensino Vocacional, instituídas na década de 1960, em São Paulo, pelo poder público. Dessa forma, observamos que o movimento citado por Barrera, que ocorre hoje, não é um movimento decorrente em resposta das tentativas organizacionais da época de 1960. Porém, não podemos negar a convergência de práticas e ideias presente nestas duas movimentações históricas dentro da educação. O que denominamos aqui, de ENT, resultam assim de uma onda de modificações curriculares e estruturais em diversas escolas que, se propõe assim a repensar não só o que é educação, mas também o porque e para que educar.

Salientamos que a sigla ENT foi um termo cunhado pela primeira autora, no decorrer da sua pesquisa. Alguns outros pesquisadores da área utilizam outras nomenclaturas tais como: escola aberta; educação viva; educação/escolas alternativa(s); escolas democráticas; entre outras mais. Neste sentido, observamos uma ausência de consenso entre os pesquisadores da área para saber como nominar tais escolas. Assim, permitimos utilizar o termo que cunhamos para apontar a ideia do movimento escolar, tal como Barrera trabalha.

Ainda sobre a temática das ENT, apontamos que, por tal tema apresentar-se como um movimento recente dentro da educação (BARRERA, 2016), a produção acadêmica a respeito das mesmas mostra-se de forma dispersa e pouco sedimentada. Para elucidarmos o que 
compreendemos por ENT trazemos aqui alguns exemplos das mudanças curriculares praticadas por estas escolas, que nos permitiram agrupá-las como objeto de estudo:

(...) foco no sujeito aprendente, divisão dos grupos por projetos de pesquisa (e não por séries/idades), modificação nos processos avaliativos, trabalho na questão da construção de valores e/ou práticas coletivas, transformação de professores específicos (por idade e/ou conteúdo) para tutores (individuais e/ou coletivos), atendimento em turno integral, participação ativa da comunidade na escola, entre outras características (FLORES e SCHWANTES, 2017b)

É importante salientar que estas escolas não se identificam como um único movimento, não trabalham de forma unificada, nem se identificam como ENT. A criação desta nomenclatura foi um dos resultados que surgiram no decorrer dos estudos desta pesquisa. Assim, ainda como exemplo de ENT, podemos citar o Projeto Âncora; A Cidade Escola Ayni; a Escola Municipal de Ensino Fundamental (EMEF) Desembargador Amorim Lima; a Escola La Cecilia; a EMEF Campos Salles; a escola da Ponte; entre outras mais.

Por fim, o objetivo deste trabalho é explorar como as ENT incluem, trabalham e desenvolvem seus currículos a partir de ferramentas do autoconhecimento, ainda assim tentando compreender como estas ferramentas atuam na constituição dos sujeitos (alunos e comunidade escolar) ali imersos e auxiliam nos diversos processos de aprendizagem.

\section{Metodologia}

A coleta de dados se originou através da produção de outro artigo das autoras, no qual o corpus de análise central era como as mídias apresentavam as ENT. Dessa forma, nossa ferramenta metodológica aproximasse do que Velasco e Díaz de Rada (2004) denominaram de snowball (bola de neve). Esta técnica de pesquisa é utilizada em trabalhos com comunidades locais onde, a partir dos aspectos que emergem nas entrevistas, o pesquisador vai desenhando o caminhar da pesquisa. Baldin e Munhoz (2011) apontam que:

Uma via para a execução desse trabalho de pesquisa em campo em comunidades é a técnica metodológica snowball, também divulgada como snowball sampling ("Bola de Neve"). Essa técnica é uma forma de amostra não probabilística utilizada em pesquisas sociais onde os participantes iniciais de um estudo indicam novos participantes que por sua vez indicam novos participantes e assim sucessivamente, até que seja alcançado o objetivo proposto (o "ponto de saturação"). O "ponto de saturação" é atingido quando os novos entrevistados passam a repetir os conteúdos já obtidos em entrevistas anteriores, sem acrescentar novas informações relevantes à pesquisa (WHA, 1994). Portanto, a snowball ("Bola de Neve") é uma técnica de amostragem que utiliza cadeias de referência, uma espécie de rede. (p. 332) 
Dessa forma, nossa aproximação ocorre, pois, nosso objeto de pesquisa centra-se nas redes que os sites da internet nos apresentam. Assim, iniciamos nossa coleta de dados a partir de duas páginas do facebook que nos serviram de ponte para chegar aos vídeos localizados na plataforma do Youtube. As páginas iniciais foram: a do professor José Pacheco, escolhida por ser uma figura bem presente nos discursos das ENT, e a página denominada Rede Educação Viva, escolhida devido à associação dela com a primeira. Estas páginas são referências no sentido de divulgarem notícias, eventos e formações voltadas ao público que busca essa educação-não-tradicional. Desta forma, ao acessarmos o conteúdo das páginas, tivemos acessos a diferentes sites que abordavam a temática das ENT a nível nacional e/ou mundial. Através dessa rede de informações disponíveis nessas páginas, chegamos então nos quatro vídeos que serão o corpus de análise deste trabalho, todos disponíveis na plataforma do Youtube para livre acesso.

Cada vídeo apresenta duração entre 30 a 40 minutos, no qual no decorrer de cada episódio, uma ENT é apresentada, ilustrando assim a rotina das escolas e as problemáticas que surgem dentro desses espaços. Para a produção deste artigo utilizamos os seguintes documentários: La Cecilia (Argentina); Escuela Democrática de Huamachuco (EDH) (Peru) e Tierra Fertil (Argentina) (todos inclusos nas referências deste trabalho). Estes vídeos fazem parte de duas séries produzidas de forma independente. Sendo assim, utilizamos três episódios do coletivo [Re]Considere e um episódio produzido pelo Canal Futura. A escolha destes vídeos se deram devida a semelhança de conteúdo presente nos materiais, uma vez que a plataforma disponibiliza outros vídeos sobre outras ENTs, optamos por focar nessas três instituições pois observávamos nelas semelhanças em suas práticas curriculares que nos chamaram a atenção e nos possibilitaram a construção desse artigo.

Feita a escolha dos vídeos, para realizar a análise dos dados, assistimos os vídeos e extraímos as falas que ilustram como o currículo destas instituições vai moldando seus sujeitos. Assim, elaboramos quadros com as falas de acordo com as semelhanças e analisamos através de referenciais citados no decorrer do artigo. As falas foram expostas na forma de quadros no sentido de facilitar a análise, pontuando no início o sujeito da fala e a qual dos vídeos/escolas a fala foi retirada. Ainda para a análise, identificamos as falas em quatro categorias comuns. Estas categorias foram surgindo à medida que as falas eram analisadas devido a sua semelhança e similaridade. 


\section{Resultados e Análise}

Para iniciarmos esta análise trazemos, primeiramente, uma questão que servirá de base para compreendermos o desenrolar do trabalho. Silva (2015) nos convida a refletir, logo nas primeiras páginas do seu livro, a definição sobre o que compreendemos acerca de currículo. No campo da educação, sabemos que não é possível definir currículo sem entramos numa série de debates e estudos teóricos, uma vez que, a compreensão do currículo está fortemente ligada a corrente teórica dos autores. Entretanto, Silva (2015) ressalta que, embora tenhamos ideias e compreensões diferentes dentro deste campo de saber, existe uma convergência sobre a temática. Pensar currículo, para o autor, é pensar qual conhecimento será ensinado. Porém, a ideia não se limita nisso. Silva ainda aponta que devemos nos questionar qual cidadão/cidadã queremos formar, afinal como o autor mesmo escreve "um currículo busca precisamente modificar as pessoas que vão "seguir" aquele currículo. (...)Qual o tipo de ser humano desejável para um determinado tipo de sociedade?" (SILVA, p.15, 2015). Assim, pensar o que é o currículo representa também pensar como iremos construir a subjetividade dos sujeitos ali imersos. Questões essas que serão exploradas e aprofundadas neste trabalho a fim de compreendermos, então, como o currículo das ENT promove os processos de subjetivação de seus sujeitos.

Iniciamos assim então, apresentando brevemente as quatro categorias que emergiram da análise do currículo das ENT. As quatro categorias foram nomeadas como (I) O exercício de Conhecer-se; (II) A Escuta Ativa e o Silêncio; (III) As Assembléias e (IV) os Exercícios de Roda e Escrita Reflexiva. Essas categorias surgiram através do caminhar da nossa pesquisa, quando observamos ser recorrente entre as ENT o exercício de auto-observação também denominado de autoconhecimento, educação emocional, inteligência afetiva, entre outros nomes. Essa prática, de conhecer-se a si parece ser uma das forças motoras dessas escolas, sendo um dos pilares estruturais dos currículos das ENT, como veremos a seguir.

Assim, trazemos já de início uma primeira reflexão. No artigo de Rêgo e Rocha (2009), as autoras iniciam apontando a questão da violência vivenciada também nos ambientes escolares:

Assistimos a uma desenfreada onda de violência nas famílias, nas escolas e na sociedade. Há menos de três décadas, os problemas mais comuns nas escolas eram: falar alto na sala, xingar ou bater em colega. Nos últimos anos, passamos a conviver com o uso de drogas ilegais e até com docentes sendo agredidos fisicamente pelos estudantes. Esse contexto leva nos a refletir sobre as emoções, especialmente as que favorecem a violência e permeiam tais situações, como, por exemplo, a raiva, a tristeza e o medo. Como possibilitar aos estudantes e aos docentes conhecerem e 
administrarem suas emoções e sentimentos, transformando a raiva, a ira, a tristeza e o medo em afeto, alegria e amor? (p.137)

As autoras apontam aqui a questão da educação emocional e como ela pode conversar com o bem estar e o equilíbrio dos sujeitos imersos na escola. Pensar a educação emocional, ou o autoconhecimento, dentro do currículo escolar, na verdade não é necessariamente uma inovação. Compreendemos, na verdade, que tais práticas surgem como uma possibilidade potencial para as escolas na nossa sociedade moderna, como reforçam as autoras acima. Assim, introduzimos aqui a nossa primeira categoria, onde abordamos exatamente sobre o Exercício de Conhecer-se, exercício esse profundamente costurado com a educação emocional pontuada pelas autoras no trecho acima. No quadro abaixo, ilustramos através das falas, como educadores, pais e alunos/alunas compreendem essa questão dentro das ENT. Vejamos:

Quadro 1 - Categoria I - O exercício de Conhecer-se

\begin{tabular}{|l|l|}
\hline $\begin{array}{l}\text { (1-Diretora/ La Cecilia): Nós dizemos que o aluno tem que } \\
\text { conhecer a si mesmo, tem que descobrir quais são as suas } \\
\text { capacidades, desenvolvê-las. Fazer disso um meio de vida } \\
\text { com sentido social. }\end{array}$ & $\begin{array}{l}\text { (2-Pacação, a nível inicial, primário e secundário era que.. as } \\
\text { crianças possam descobrir quem são, aquilo que gostam mais } \\
\text { nessa vida e poder fazer disso que gostam tanto, e lhes } \\
\text { apaixona, um meio de vida. }\end{array}$ \\
\hline $\begin{array}{l}\text { (3-Ex-aluna/La Cecilia): Esse tipo de educação depois me } \\
\text { permitiu (...) tomar decisões sobre a minha vida sem o peso } \\
\text { da minha família, do meu grupo de amigos... ou... não sei... } \\
\text { inclusive da própria escola. Ou do que a sociedade espera } \\
\text { que a gente faça... }\end{array}$ & $\begin{array}{l}\text { (4-Ex-aluna/ La Cecilia): As aulas de autoconhecimento, } \\
\text { para isso (escolher um curso a nível superior) me serviram de } \\
\text { realmente gostaria de fazer com a minha vida é... dedicar-me } \\
\text { ao jornalismo o }\end{array}$ \\
\hline $\begin{array}{l}\text { (5-Educadora/EDH): Para mim pessoalmente, por exemplo, } \\
\text { quando eu me incorporei a escola democrática foi muito } \\
\text { difícil. Quando eu entrei era muito forte para mim, porque } \\
\text { eu tinha que aprender a aceitar que os outros me diziam as } \\
\text { minhas verdades... ou as críticas que me diziam para } \\
\text { pensarmos e melhorar. }\end{array}$ & $\begin{array}{l}\text { (6-Aluna/EDH) Em outras escolas, quando eu dizia algo a } \\
\text { alguém, que não gostei do que ele me fez, a pessoa se } \\
\text { para mudarem. E ninguém se incomoda com isso. }\end{array}$ \\
\hline
\end{tabular}
Fonte: produzido pela autora.

Observamos nas falas dos sujeitos três pontos que destacaremos. Primeiro, a consciência e a clareza dos pais e da comunidade escolar em compreender que, nas ENT a prática do conhecer a si faz parte da formação dos sujeitos e assim, consequentemente, do currículo escolar. Isso é um dado importante que vem surgindo no decorrer da construção da pesquisa, uma das forças que movem os pais a procurarem ENT é exatamente a compreensão 
de que, na visão deles, falta algo no currículo das demais escolas, e a ampliação curricular e temporal das ENT parece, por vezes, sanar esta ausência. $\mathrm{O}$ autoconhecimento é um ponto muito forte das ENT, sendo muitas vezes a força que norteia essas escolas - o exercício de cuidar de si. Assim, podemos ver tais questões ilustradas nas falas do pai e da diretora do La Cecilia. Paralelo a isso, notamos, num segundo momento, alguns dos reflexos que este exercício do conhecer-se a si desenrola nos sujeitos. As falas das ex-alunas do La Cecilia apontam esse caminho, ilustrando como esse exercício de se conhecer e se observar as auxiliou na momento de fazerem escolhas futuras. Na fala das ex-alunas é possível observar a segurança quanto a tomada de decisões, assim como, a clareza sobre o processo que é tomar uma decisão. Esses pontos seguem ao encontro do que Rêgo e Rocha (2009) apontam sobre a questão dos sujeitos tornarem-se emocionalmente responsáveis, no sentido das jovens terem clareza, não somente sobre o que engloba a tomada de decisão e/ou outro sentimento em si, mas também, sobre os diferentes fatores que envolvem estas questões como, por exemplo, os contextos culturais, familiares, sociais, entre outros. A educação emocional, como aponta Rêgo e Rocha (2009), nos auxilia também a compreender qual o peso de cada contexto e como lidar de forma equilibrada com essas emoções.

Já nas falas da Escola Democrática de Huamachuco (EDH), observamos a questão da nitidez dos sentimentos dos sujeitos ali imersos acerca das suas próprias emoções. Na primeira fala, a educadora aponta a sua dificuldade inicial no trabalho, uma vez que se sentia exposta aos demais por ter que lidar com as críticas feita pelos demais sujeitos presentes na escola. Em paralelo, podemos observar a facilidade da criança, no caso, a aluna, ao expor suas insatisfações perante os demais. Ela aponta " Mas aqui, as pessoas gostam que a gente fale o que elas fizeram de errado, para mudarem. E ninguém se incomoda com isso". É interessante observar essas duas falas juntas pois, compreendemos que elas se complementam e, para além, elas ilustram o processo do autoconhecimento em ação. No caso da educadora, ela aponta a dificuldade inicial de ser criticada, de ser convidada a repensar alguma estratégia ou atitude. Já a menina, que se desenvolveu dentro da escola, imersa nesses processos de reflexão e auto-reflexão, aponta com tranqüilidade como ela se sente segura em expor suas ideias, sentimentos e insatisfações nesse ambiente. No trabalho de Rêgo e Rocha (2009), as autoras apontam exatamente como esse exercício de reconhecer-se pode auxiliar na construção dos sujeitos emocionalmente responsáveis em dois pontos, afirmando que:

Na Educação Emocional, aprendemos quando, onde e como expressar os próprios sentimentos, e de que maneira eles influenciam outras pessoas, assumindo a responsabilidade pelas consequências desses sentimentos (...) O ser responsável pela 
própria conduta, favorecerá ao educando agir de forma ética e acima de qualquer restrição; aprender a angariar confiança por meio de sua autenticidade; admitir os próprios erros; e assumir posições firmes e coerentes, mesmo que não sejam do agrado geral (p.143;p.144).

Assim, observamos nessa primeira categoria dois pontos principais do que denominamos de o Exercício de Conhecer-se. O primeiro ponto é a proposta, nas ENT a construção da relação com os pais e com a comunidade escolar se dá principalmente através do diálogo. Nos vídeos, é possível observar isso com maiores detalhes, mas o que chamamos a atenção aqui é a questão da sinceridade, tanto da diretora, quanto dos pais, em relação a proposta da escola. A proposta é clara, como diz a diretora "Nós dizemos que o aluno tem que conhecer a si mesmo (..) " e esse é um ponto a ser observado, pois o autoconhecimento não apenas perpassa o currículo por entre as aulas de matemática ou ciência, ele está ali, demarcando seu espaço assim como as demais disciplinas nas ENT. O segundo ponto que salientamos é a questão de como essas aulas de autoconhecimento vão auxiliando na construção da subjetividade dos sujeitos. Isso é possível observar nas demais falas, tanto das ex alunas que apontam o auxílio dessa ferramenta nos seus processos de tomadas de decisão, como nas falas da escola EDH, nas quais a educadora e a aluna apontam como se sentem ao exporem seus sentimentos e, também, ao serem convidadas pelos colegas a refletirem sobre suas ações. O processo de empoderamento da educadora no decorrer do vídeo é muito interessante, pois no avançar do capítulo ela vai apresentando um pouco mais sobre si e sobre os processos que a escola EDH provoca e provocou nela como educadora.

$\mathrm{Na}$ segunda categoria, observamos o surgimento da questão da Escuta Ativa, acompanhadas com as práticas meditativas que ocorrem nas ENT. Nas falas, podemos perceber como o exercício da escuta ativa permeou e permeia não somente os processos de aprendizagem, mas também a construção da subjetividade dos sujeitos:

Quadro 2 - Categoria II - A Escuta Ativa e o Silêncio

\begin{tabular}{|l|l}
\hline (1-Aluna/La Cecilia) O momento de silêncio é um momento para acalmar a & (2- Aluno/ La Cecilia) O silêncio é para te \\
mente antes de começarmos a jornada todos juntos. Apesar de ser opcional, a & relaxar, te tranquilizar. São quinze minutos \\
gente faz silêncio porque a maioria dos alunos já está lá dentro (no saguão). & para te tranquilizar e... como é que se fala? \\
(...) Depois de um tempo na escola a gente se interessa e vai compreendendo & Começar a manhã bem. \\
que o silêncio é uma espécie de exercício mental, como uma situação mental \\
que é bastante interessante e útil. A gente se sente em ordem, se assim quiser. \\
Depois isso se perde, bastante rápido, com todos os mecanismos da mente, \\
mas, quando se faz todos os dias vai se aprendendo a utilizá-lo e às vezes se \\
encontramos em situações diárias utilizando o silêncio
\end{tabular}


(3-Educador/ La Cecilia) Eu vejo que em algumas escolas tradicionais há muitos resultados bonitos, lindos. Mas, onde o clima desse trabalho depende exclusivamente do educador. Onde inclusive o silêncio necessário para fazer música é algo que é imposto pelo educador. E aqui construímos entre todos. Isso me parece apaixonante, me encanta que isso aconteça.

(5-Aluna/EDH) Entre os acompanhantes (educadores) e as crianças nós nos entendemos. Porque os adultos não dizem: " Ah eu sou grande e você deve me obedecer." (...) Não. Nós decidimos por nós mesmos e os acompanhantes estão aqui para nos apoiar.

(7-Aluna/ EDH): Antes, Enrique (um educador) chegou aqui muito machista. Então, nós lhe ensinamos para que não seja machista. Então ele disse: desculpe também e eu não vou voltar a fazer. E com a ajuda da gente Enrique agora não é mais assim e mudou.
(4-Aluno/EDH) Você pode estar por todos os lados, mas sempre consciente dos demais, para não incomodar, porque às vezes estão trabalhando (...) então você passa, e às vezes interrompe o trabalho deles.

(6-Aluna/ EDH): Supostamente, nos outros colégios: "Se você é pequeno sua opinião me faz rir". Mas aqui, nessa escola, os grandes respeitam a opinião dos pequenos

(8-Educadora/EDH) Assim... quando eles corrigem nossos erros... para mim está tudo bem, pois me faz crescer como pessoa e aprendo muito mais com eles

Fonte: produzido pela autora.

Neste quadro observamos, primeiramente, o silêncio em três momentos diferentes: $1^{\circ}$ ) como ferramenta meditativa; $2^{\circ}$ ) como elemento da relação entre os sujeitos, elemento esse costurado profundamente com a questão do respeito com o outro; $3^{\circ}$ ) a questão do silêncio como ferramenta de escuta, ponto esse que podemos observar nas últimas quatro falas. Nesse ponto, costuramos a questão do silêncio associado a comunicação-não-violenta, também denominada por alguns pesquisadores como escuta ativa.

Quando apresentamos a questão do silêncio dentro do campo de saberes da educação é interessante observamos a diferença entre as definições que o silêncio pode apresentar. Neste campo de saberes, observamos que essa palavra surge, em sua maioria, relacionada ao ato de silenciar, ou ainda das vozes silenciadas, surgindo assim como ferramenta de controle dentro dos ambientes escolares. Entretanto, aqui traremos o silêncio com outra conotação, exploraremos o seu sentido como um ato meditativo e/ou reflexivo questão essa apresentada pelas ENT em seus processos curriculares. Assim, observamos já, nas duas primeiras falas que ilustram o quadro, como os alunos utilizam dessa ferramenta para a construção das suas subjetividades e, também, para auxiliá-los a responder aos processos externos, como observamos na parte final do vídeo do projeto Tierra Fertil. No final do episódio, observamos um conflito entre uma educadora e um educando. Na tentativa de buscarem uma resolução, ambos convocam uma assembléia estudantil. Porém, o educando não se mostra aberto a discussão, assim, a educadora e os demais colegas optam pela prática de meditação. Após a meditação, ambos, educando e educadora conseguem conversar e resolver seu conflito de forma harmônica. Essa parte do vídeo é ilustrada principalmente por imagens. Nesse ponto, observamos a importância do exercício meditativo associado a prática do silêncio como ato de 
reflexão. É muito interessante observar a mudança comportamental do educando e da educadora perante as situações, tanto dos estados emocionais como para a abertura para o diálogo. Esse ponto parece também ilustrado na primeira fala do quadro, quando um aluno de La Cecilia aponta suas compreensões a cerca de como utilizar o silêncio "(...) mas, quando se faz todos os dias vai se aprendendo a utilizá-lo e às vezes se encontramos em situações diárias utilizando o silêncio".

Observamos que as ENT utilizam destes mecanismos não somente para a resolução de conflitos, mas também como prática integral do currículo, no qual uma das diretrizes é, como já citamos acima, o processo do autoconhecimento. Deste modo, trazemos o trabalho de Marques, Rocha e Flores (2015), no qual as pesquisadoras apontam como a meditação pode auxiliar na construção de uma educação integral, auxiliando os sujeitos a melhor se conhecerem:

\footnotetext{
Meditar proporciona ampliação das capacidades perceptivas e interpretativas, pois envolve contemplação, avaliação e tomada de decisão; amplia o poder criativo e renova o sentido de pertencimento ao coletivo. A meditação é a realização da vida presente, do agora construído historicamente e propicia o autoconhecimento, contribuindo para a formação plena do sujeito. (...) Na Educação Básica, a meditação pode ser utilizada para proporcionar um estado de relaxamento físico e mental, a fim de desenvolver a consciência do indivíduo, aluno. Para que, deste modo, seja facilitada a percepção da aprendizagem no inconsciente de cada uma das crianças (p.408).
}

Seguindo então a nossa análise, quando observamos a terceira e a quarta fala do quadro II, podemos ver a questão de como o silêncio está profundamente relacionado a questões de respeito e cuidado para com os demais. Ponto esse muito explorado nas ENT: a construção de uma identidade individual e ao mesmo tempo coletiva. Na fala número 3, observamos primeiramente, que o educador salienta a diferença de como o silêncio, na perspectiva dele, se constrói em uma escola dita tradicional e em uma ENT. Em sua fala, podemos observar como ele compreende e aponta esse silêncio como uma construção do coletivo, necessária a aprendizagem. Porém, não imposta, mas sim construída na base das relações com os sujeitos ali imersos. Nas imagens seguintes do vídeo, quando o educador desenrola essa questão, podemos observar através dos/das alunos/alunas e suas interlocuções como esse processo vai se desenvolvendo. É interessante observar que estes processos não se dão forma linear e pronta, como se os educadores das ENT tivessem receitas "mágicas". Mas, no desenrolar de cada episódio observamos o dinamismo desses processos, assim como os movimentos fluidos dos sujeitos que se propõem a ali estarem. Como metáfora, podemos pensar no antigo hábito de pular corda, onde precisamos estar atentas ao ritmo, mas precisamos ao mesmo tempo nos soltarmos e confiarmos naquele movimento, para 
conseguirmos desfrutar da brincadeira de forma plena. Acompanhando a nossa metáfora, observamos nos quatro vídeos este movimento não só nos educadores, mas em toda a comunidade escolar ali presente. Vemos uma atenção focada ao desenvolvimento do grupo, porém, junto a isso, um movimento fluido no sentido de conseguir acompanhar os limites dos sujeitos ali presentes respeitando sempre a construção através do coletivo. O respeito ao outro, se dá quando nos permitimos não apenas fazer silêncio para que o outro ou a outra possa realizar suas atividades, mas também, quando nos permitidos silenciarmos e escutarmos os que estão ao nosso redor com profundidade e sinceridade, de forma desarmada.

Assim, trazemos então, nosso último ponto de análise deste quadro - a Escuta Ativa dentro das ENT. Reforçando a ideia acima, a escuta ativa não é o ato de simplesmente ouvir, mas sim, escutar a alguém. Essa ferramenta vem sendo utilizada de forma ampla nas áreas da saúde como: enfermagem, psicologia e demais áreas terapêuticas (CARVALHO e MESQUITA, 2014). Hoje, observamos também, a utilização dela dentro das ENT como ponto norteador nos currículos, principalmente em questões como mediação de conflitos. Por ser utilizada em diversos campos de saberes, ocorre que, na literatura, a escuta ativa recebe uma série de nomes, tais como: escuta integral, escuta terapêutica, escuta atenta, entre outros, como ilustra Carvalho e Mesquita (2014) em seu trabalho no qual apontam os benefícios dessa ferramenta, mostrando que:

\begin{abstract}
A escuta apresenta-se como uma estratégia de comunicação essencial para a compreensão do outro, pois é uma atitude positiva de calor, interesse e respeito, sendo assim terapêutica (...) A Escuta Terapêutica pode ser definida como um método de responder aos outros de forma a incentivar uma melhor comunicação e compreensão mais clara das preocupações pessoais. É um evento ativo e dinâmico, que exige esforço por parte do ouvinte a identificar os aspectos verbais e não verbais da comunicação (...) No cuidado, a escuta pode minimizar as angústias e diminuir o sofrimento do assistido, pois por meio do diálogo que se desenvolve, possibilita ao indivíduo ouvir o que está proferindo, induzindo-o a uma autorreflexão. A prática da escuta significa o reconhecimento do sofrimento do paciente, pois o ato de ouvir assume que há algo para se ouvir, oferecendo a este a oportunidade de falar e expressar-se. Ainda, a escuta é um instrumento importante para a obtenção de informações, por exemplo, pelo uso de perguntas abertas, resumos e esclarecimento (p.1128) .
\end{abstract}

Assim, podemos observar nas últimas quatro falas do quadro II como a escuta ativa perpassa a os sujeitos ali imersos nas ENT. Uma das falas mais simbólicas, para as autoras, foi a fala 6 , na qual podemos observar o ponto central da escuta ativa - quando o sujeito que fala, se sente de fato ouvido, e assim, reconhecido, representado e, também, respeitado. A fala 5 , de outra aluna da mesma escola, reforça essa ideia, apontando o reconhecimento e o respeito dos docentes para com os discentes. Nas últimas duas falas, também proferidas por 
sujeitos da $\mathrm{EDH}$, notamos a questão da autorreflexão, ponto esse trazido por Carvalho e Mesquita (2014) no fragmento acima. Quando a educadora discorre sobre como ela se sente ao ouvir seus alunos falarem a respeito das práticas pedagógicas, ela entra em dois movimentos. O primeiro, é o da prática da escuta ativa, na qual a educadora entra num movimento de entrega e abertura, para ouvir o que os demais sujeitos tem a falar a respeito do trabalho dela. O segundo movimento que percebemos, é a questão da autorreflexão, quando a educadora, na fala 8, aponta "(...) para mim está tudo bem, pois me faz crescer como pessoa e aprendo muito mais com eles", demonstrando ali o processo de dinamismo, interesse e respeito construído a partir da escuta ativa, que por sua vez, acaba funcionando como um estímulo para que a educadora revise e repense a sua prática. Esses movimentos refletem no que discutimos lá no primeiro quadro pois, quando a educadora repensa e ou revisa a sua prática, ela está, para além de uma mera reconstrução burocrática de seu trabalho, fazendo um exercício de conhecer a si mesma, ponto chave nas ENT - o dinâmico e contínuo processo de auto-observação.

Por fim, pensando ainda na questão da escuta ativa, observamos como a aluna compreende esse processo quando ela relata o caso do educador machista, na fala 7. Nesse caso, a aluna reconhece, primeiramente que ela e seu grupo foram ouvidas, em segundo plano, observamos através da fala dela e das imagens que seguem no documentário, o posicionamento do educador perante o grupo. A postura do educador ilustra a questão da auto-reflexão, já a fala da aluna nos demonstra alguns dos efeitos da escuta ativa nos sujeitos envolvidos, não somente daqueles que se dispõe a falar, mas principalmente daqueles que se dispõem a escutar. Um dos eixos principais da escuta ativa é o exercício de escutar, acolher e refletir o conteúdo exposto na fala, tentando compreender não somente o que foi dito, mas todas as nuances expostas no corpo, nos gestos, no tom da voz, no posicionamento daquele que fala, e principalmente nos sentimentos ali demonstrados (CARVALHO E MESQUITA, 2014). Esse exercício pode ser observado nas reflexões que os fragmentos acima nos trazem, assim como, nas inúmeras imagens dos vídeos nas quais o silêncio guarda profundas reflexões dos sujeitos ali presentes.

Finalizando então a análise dessa segunda categoria, observamos que: primeiro o exercício meditativo, o silêncio e a escuta ativa são elementos presente nos currículos das ENT, sendo utilizados como ferramentas para o caminho da auto-percepção e do autoconhecimento. Essas ferramentas estão profundamente conectadas, sendo assim necessário compreendê-las como elementos interligados no grande contexto, uma vez que, o silêncio é necessário dentro da escuta ativa, assim como, para conseguirmos expor com qualidade o que 
sentimos é possível usar da meditação como ferramenta para silenciarmos os ânimos e nos concentrarmos. Além disso, conseguimos ver o silêncio em suas duas facetas, servindo de ponte, ora quando os sujeitos estão sozinhos e buscam reflexão sobre si, ora quando os sujeitos estão em grupo e buscam compreender melhor o outro, como um dos alunos pontua na fala 2: "o silêncio é para te relaxar, te tranquilizar. São quinze minutos para te tranquilizar e... como é que se fala? Começar a manhã bem."

Na categoria III, observamos uma outra característica importante também recorrente dentro das ENT - a construção das assembléias estudantis. As assembléias são práticas comuns às ENT, utilizadas principalmente para a resolução de conflitos, debates, tomadas de decisões, planejamentos, entre outras possibilidades. O professor José Pacheco, um dos fundadores da Escola da Ponte, define em um de seus livros as assembléias como:

[...] dispositivo de intervenção direta, a assembleia de Escola é a estrutura de organização educativa que proporciona e garante a participação democrática dos alunos na tomada de decisões que respeitam à organização e funcionamento da Escola (PACHECO E PACHECO, 2015, p.121).

Abaixo então, ilustramos através das falas a utilização deste dispositivo nas ENT. É interessante observar nas falas como os/as alunos/alunas e demais componentes da comunidade docente percebem e compreendem o papel da assembléia.

\section{Quadro 3 - Categoria III - As Assembléias}

\begin{tabular}{|c|c|}
\hline $\begin{array}{l}\text { (1-Aluno/EDH) Eu gosto de cinema, averiguar se as coisas } \\
\text { são boas ou más (fala em relação ao exercício de pesquisar). } \\
\text { Tipo Dragon Ball (desenho animado), estamos vendo, porque } \\
\text { vamos enviar à assembléia. Porque Dragon Ball ensina as } \\
\text { crianças a brigar... às vezes têm poderes e as crianças pensam } \\
\text { que vão ter poderes também... por isso está proibido. É muita } \\
\text { briga... Muita briga e as crianças aprendem a brigar. Então } \\
\text { nós estamos vendo este tema para levar a assembleia e ver o } \\
\text { que nos parece... }\end{array}$ & $\begin{array}{l}\text { (2-Aluno/La Cecilia): A assembléia foi criada como um } \\
\text { espaço de ordem, soa muito autoritário, mas não é. É um } \\
\text { espaço onde se coloca toda a escola a par do que acontece e } \\
\text { onde se discute coisas de interesse comum. E, às vezes, se } \\
\text { usa para outras questões mais existenciais. Ou problemas } \\
\text { referentes a algum aluno... }\end{array}$ \\
\hline $\begin{array}{l}\text { (3-Mãe de aluna/ EDH) Bom, uma história engraçada que } \\
\text { temos com Luna e a escola democrática é que uma vez não } \\
\text { estávamos de acordo sobre quem iria cozinhar. Eu queria que } \\
\text { Roberth cozinhasse, ele queria que cozinhássemos todos. } \\
\text { Então Luna disse: "Assembleia!". "Propostas! eu proponho } \\
\text { que todos devem opinar" (...) E no final Luna disse: o que } \\
\text { acontece é que somos uma família, e todos temos que } \\
\text { cozinhar." E assim todos fomos cozinhar depois da } \\
\text { assembleia de Luna. }\end{array}$ & $\begin{array}{l}\text { (4-Pai de aluna/ EDH) A mim, me gostou muito o fato de } \\
\text { terem uma assembléia, não? Uma assembléia na qual eles } \\
\text { podem eliminar suas contradições. Romper algumas regras } \\
\text { que são pauta necessárias nas atividades humanas. E mais... } \\
\text { eu disse um dia: Filha, Na assembléia, como vocês } \\
\text { discutem, propõe, questionam? Ela me disse: papai, eu } \\
\text { agora tenho um cargo. Qual é esse cargo? Eu sou } \\
\text { conciliadora. O que significa isso, querida? Papai, antes de } \\
\text { citar alguém na assembléia que fez algo que não nos }\end{array}$ \\
\hline
\end{tabular}




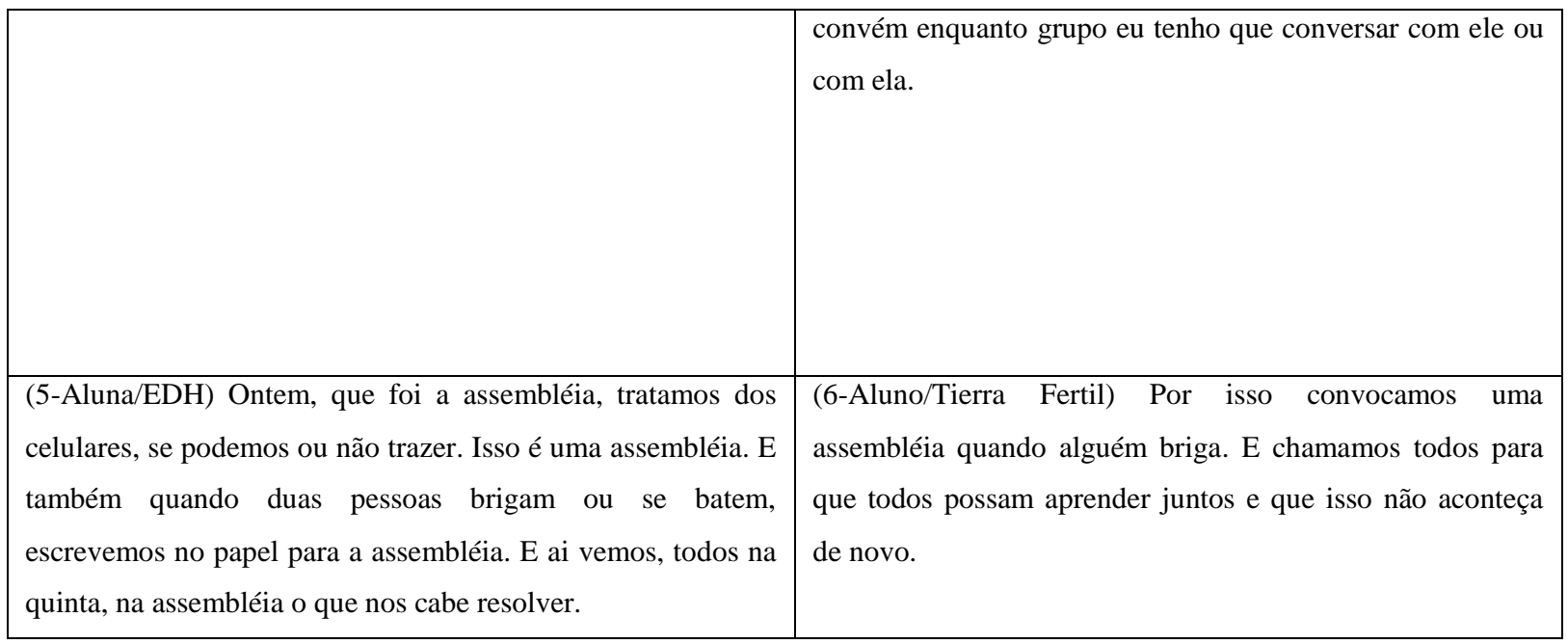

Fonte: produzido pela autora.

Se retomarmos ao que já analisamos, podemos observar nos trechos acima que, nas assembléias, os momentos de silêncio e os exercícios contínuo de diálogo utilizam a questão da escuta ativa e do silêncio como embasamento. Assim, observamos como os elementos da categoria II com a categoria III vão se conectando. Além disso, uma das falas desse quadro, nos aponta algumas das possibilidades que as assembléias trazem, como o aluno mesmo ilustra na fala 2: "é um espaço onde se coloca toda a escola a par do que acontece e onde se discute coisas de interesse comum. E, às vezes, se usa para outras questões mais existenciais". No trecho acima, percebemos que o espaço das assembléias também é utilizado para o exercício do autoconhecimento, questão essa trabalhada na nossa primeira categoria. Outra questão que observamos é a utilização de um dos campos de saberes da psicologia denominado de Comunicação-Não-Violenta (CNV). A CNV foi estruturada nos anos sessenta, pelo psicólogo pesquisador Marshall Rosenberg foi definida como:

\begin{abstract}
A CNV nos ajuda a reformular a maneira pela qual nos expressamos e ouvimos os outros. Nossas palavras, em vez de serem reações repetitivas e automáticas, tornamse respostas conscientes, firmemente baseadas na consciência do que estamos percebendo, sentindo e desejando. Somos levados a nos expressar com honestidade e clareza, ao mesmo tempo em que damos aos outros uma atenção respeitosa e empática. Em toda troca, acabamos escutando nossas necessidades mais profundas e as dos outros. A CNV nos ensina a observarmos cuidadosamente (e sermos capazes de identificar) os comportamentos e as condições que estão nos afetando. Aprendemos a identificar e a articular claramente o que de fato desejamos em determinada situação. A forma é simples, mas profundamente transformadora (ROSENBERG, 2006, p. 21,22).
\end{abstract}

Dentre os vídeos, conseguimos perceber uma forte tendência à inclusão da $\mathrm{CNV}$, uma vez que, o exercício de se expressar perante o grupo, é um dos exercícios mais trabalhados dentro das assembléias. Salientamos que em nenhum momento dos vídeos foi apontado ou 
citado pelos educadores a utilização do que se tem chamado de CNV como prática recorrente nas ENT. Entretanto, observamos que as assembléias são espaços que utilizam, de forma ampla, as ferramentas desenvolvidas por Rosenberg, nos permitindo assim entrecruzar estas duas técnicas: a assembléia e a CNV. Podemos observar, também, em diferentes momentos dos vídeos, como as crianças, os/as jovens e também os/as educadores/educadoras são convidados a fazer exercícios propostos pela CNV. Porém, as ENT não trabalham com a questão do expor-se pelo simples fato de se expor, mas sim, de, através da fala exercitar o cuidado com o outro e, também, o cuidado consigo mesmo. Quando mencionamos o cuidado consigo, percebe-se um dos pontos principais da CNV, uma vez que, este campo de saber não é somente uma técnica para aprimorarmos o que falamos, mas é compreendida como um exercício de conhecer-se. Ela convida a refletir profundamente acerca dos próprios sentimentos antes de expor-se (ROSENBERG, 2006). Assim, a CNV, parece estar presente nas assembléias e também em outros espaços das ENT, conversando com a questão da educação emocional, questão essa citada no início desse trabalho.

Como mencionamos anteriormente, outra conexão que notamos é a presença da escuta ativa dentro das assembléias. O conjunto da CNV e da escuta ativa possibilita os/as estudantes acessarem seus sentimentos, desejos e ânsias com maior clareza. Esta possibilidade, como demonstrada nas falas, auxiliam tanto na resolução dos conflitos, como nas decisões necessárias a serem tomadas nas vidas dos sujeitos. É interessante salientar ainda, que no decorrer do vídeo observamos os processos de desconforto que por vezes a prática da assembléia pode trazer, ponto esse ilustrado na fala 3, de uma das mãe da escola EDH. Notamos, através da fala e das imagens, como alguns desconfortos promovem a reflexão, que assim, movimenta os sujeitos, auxiliando-os, mais uma vez, em seus processos de autoconhecimento tanto dentro como fora da escola.

Nas falas dos/das alunos/alunas da escola EDH e da escola Tierra Fertil notamos uma das principais funções das assembléias nas escolas - tomada de decisão coletiva. Na fala desses sujeitos, observamos que, nos três momentos, ocorre algo em comum: eles querem discutir a possibilidade de um novo horizonte. Seja para resolver um conflito, seja para refletir sobre o que pode ou não ser feito dentro do ambiente escolar, as assembléias funcionam como um espaço democrático onde os sujeitos podem expor suas dificuldades, insatisfações, anseios e demais assuntos que o grupo considere pertinente. É interessante observar como as ENT buscam medidas conciliadoras dentro do ambiente escolar através das assembléias. $\mathrm{O}$ episódio sobre a ENT Tierra Fertil ilustra bem isso, quando observamos o conflito entre uma das educadoras e um educando. Sobre esse conflito, podemos ainda pensar sobre a fala 6 de 
um aluno: "e chamamos todos para que todos possam aprender juntos e que isso não aconteça de novo". Nesse recorte, observamos novamente alguns pontos já trabalhados aqui como os processos de subjetivação através do coletivo e da escuta ativa. O episódio da EDH também ilustra isso, principalmente trazendo alguns dos recortes dos processos de mediação pré assembléias, como bem ilustra a fala 4 do pai de uma aluna dessa escola.

Assim, as assembléias, como notamos, podem ser motivadas por diferentes razões. Entretanto, sua função principal é trabalhar a questão da resolução de conflitos de forma harmônica em grandes grupos. Além disso, as assembléias funcionam como excelentes dispositivos para que a comunidade escolar trabalhe: a escuta ativa, a CNV, o silêncio meditativo, os processos de argumentação, e, também, o processo de autoconhecimento, reflexo das demais categorias que apresentamos acima. É interessante observar uma das reflexões que um dos alunos da escola La Cecília faz, na fala 2 "a assembléia foi criada como um espaço de ordem, soa muito autoritário, mas não é. É um espaço onde se coloca toda a escola a par do que acontece e onde se discute coisas de interesse comum". Ele aponta primeiramente, que de fato o espaço das assembléias representa uma certa hierarquização, porém, ele mesmo ressalta apontando que a forma como ocorre dilui o poder do dispositivo, tornando um ambiente confortável no qual os sujeitos conseguem se expor e dialogar sobre as diversas problemáticas do espaço.

Finalizando então a nossa análise, partimos para a categoria IV, observada nos vídeos. Nessa última categoria, apontamos como o desenvolvimento dos trabalhos em grupo através de: cirandas, projetos, encontros matinais e outras práticas auxiliam no processo de individuação dos sujeitos, de tal modo como na construção de uma identidade do/com o coletivo. Essa é uma característica bem pertinente das ENT - o respeito ao eu individual, construído em paralelo com uma responsabilidade social com o coletivo. Assim, percebemos dois momentos nos vídeos, os processos de grupo e os processos individuais, ambos auxiliando os sujeitos a construírem suas subjetividades. Vejamos:

Quadro 4 - Categoria IV - Exercícios de Roda e Escrita Reflexiva

\begin{tabular}{|l|l|}
\hline $\begin{array}{l}\text { (1- Aluno/ La Cecilia): Pelo menos o que eu sinto é } \\
\text { como um grupo de gente que está fazendo uma mesma }\end{array}$ & $\begin{array}{l}\text { (2-Aluno/ Tierra Fertil) Quando chegamos fizemos uma roda e } \\
\text { explicamos o que vamos fazer no dia ou se existe algo especial... } \\
\text { coisa. No círculo a gente que tem o mesmo objetivo. E } \\
\text { as aulas se constroem tanto pelos professores quanto } \\
\text { pelos estudantes... }\end{array}$ \\
\hline $\begin{array}{l}\text { (3-Aluno/EDH) Pela manhã, quando chegamos sempre falamos todos sobre o que vamos fazer no dia. } \\
\text { fazemos um círculo matinal. Cantamos, brincamos, nos }\end{array}$ & que fazemos num caderno (...) A bitácora é como se fosse um \\
\hline
\end{tabular}


RELACult - Revista Latino-Americana de Estudos em Cultura e Sociedade

\begin{tabular}{|c|c|}
\hline $\begin{array}{l}\text { divertimos... e depois vamos a outros espaços e } \\
\text { fazemos o que devemos fazer. }\end{array}$ & $\begin{array}{l}\text { diário... tem que escrever tudo que você fez no dia. Se você tem } \\
\text { vontade, escreve uma ou duas coisas, mas eu sempre escrevo tudo } \\
\text { que fiz no dia. }\end{array}$ \\
\hline $\begin{array}{l}\text { (5-Educadora/ La Cecilia): Se tivermos que nomear } \\
\text { algumas características, que nos diferem das outras } \\
\text { escolas seriam: A flexibilidade que temos. A atenção } \\
\text { personalizada para cada criança. Aqui as crianças estão } \\
\text { divididas por grupos. Isso já é outra diferença. Temos } \\
\text { os grupos sócio-afetivos, como chamamos. (...) Temos, } \\
\text { também, as salas abertas, o que permite a criança } \\
\text { gestionar/participar de outra atividade. Em um grupo } \\
\text { mais avançado, por exemplo. Também temos } \\
\text { autogestão. As crianças gestionam as próprias } \\
\text { atividades. Deixamos que as crianças escolham, por } \\
\text { seus próprios interesses, gostos e desejos... seus jogos e } \\
\text { atividades. E deste jogo realizamos as aprendizagens } \\
\text { pedagógicas. }\end{array}$ & $\begin{array}{l}\text { (6-Educadora/ Tierra Fertil): Sabemos que as crianças aprendem } \\
\text { com seus pares, com o ambiente, com os materiais e com os } \\
\text { adultos que estão com eles. Então jogamos com essas variáveis. } \\
\text { Sabemos que a aprendizagem é integral, de verdade. Então } \\
\text { fazemos com que as coisas aconteçam e acompanhamos... }\end{array}$ \\
\hline
\end{tabular}

Fonte: produzido pela autora.

Uma das principais características da categoria IV é a questão do desenvolvimento dos trabalhos em grupo. As falas acima, retratam parte desse currículo que preza pelo coletivo, porém a maior riqueza de detalhes está nas imagens.

Observando as três primeiras falas dos alunos, sendo um de cada instituição, estes trazem a questão do desenvolvimento desse currículo coletivo, no qual saber trabalhar em grupo é uma diretriz necessária aos sujeitos ali imersos. Em suas falas, eles ilustram a rotina da escola, na qual os momentos de partilha em grupo sempre iniciam os trabalhos de manhã e muitas vezes também, encerram os trabalhos no final do expediente. A fala 1 de um dos alunos da escola La Cecilia aponta, na nossa compreensão, uma das maiores características do currículo das ENT, ele afirma que: "no círculo a gente que tem o mesmo objetivo (...)". O trabalho em grupo nessas escolas, não somente é utilizado como ferramenta para trabalhos pedagógicos, como também é responsável por direcionar os processos de autoconhecimento que citamos acima. Pois, nos grupos, todos os exercícios que mencionamos são realizados a todo instante: a escuta ativa, a $\mathrm{CNV}$, a meditação e, também, o exercício do silêncio. É possível observar estes processos ocorrendo a medida que os vídeos se desenvolvem, uma vez que, os currículos destas escolas são majoritariamente pautados em grupos de estudos e projetos, assim, observamos os jovens e crianças interagindo o tempo todo com o coletivo. Junto a isso, podemos olhar as falas 5 e 6 que, reforçam assim a importância do trabalho em 
grupo nas ENT. As duas educadoras, sendo cada uma de uma instituição diferente, apontam exatamente a importância que a escola dá para que os educandos trabalhem aos pares e em grupos, chamados por sócio-afetivos, nas palavras da própria educadora.

Nas falas 5 e 6, das educadoras, notamos ainda outra questão bem recorrente nas ENT, a questão da auto-gestão do tempo da criança/jovem. Gestar o próprio tempo é um desafio atual na nossa sociedade contemporânea, e as ENT apresentam essa característica em evidência em seus currículos, uma vez que, o desenvolvimento dos trabalhos dos/das educandos/educandas está majoritariamente centrado no tempo do indivíduo. Como estas escolas não apresentam séries, os sujeitos desenvolvem seus currículos a partir de projetos, nos quais os interesses pessoais norteiam a escolha das temáticas. Nesse sentido, observamos novamente a questão do exercício de conhecer a si mesmo, ponto que trabalhamos na primeira categoria. Quando os sujeitos iniciam seus processos de aprendizagem a partir de necessidades e curiosidades pessoais, além da aprendizagem se tornar mais interessante para o sujeito, ocorre nessa prática um exercício reflexivo de olhar para si. Quando se reflete sobre o que se quer aprender, se reflete também sobre possuir dúvidas em relação ao mundo em se vive, quais as habilidades que se quer desenvolver, e se reconhece nesse exercício também quais pontos não agradam ou se distanciam do desejo de aprender. Essas reflexões fazem parte do exercício de conhecer a si, prática norteadora das ENT, como observamos nesse trabalho.

Neste sentido, podemos notar a fala 4 de dois educandos da Tierra Fertil. A fala desses sujeitos ilustra, mais uma vez, a questão da auto-observação. Quando se realiza o exercício de expressar-se em um papel ou em outro espaço a rotina, os sentimentos ou os anseios, exercitamos novamente um olhar para si. A escrita reflexiva, como denominamos essa prática, vem em paralelo com o exercício de auto-gestão do próprio tempo. Ao registrar no caderno as práticas realizadas durante um dia, consegue-se observar com maior clareza como manejar esse tempo e também conhecer os próprios limites acerca de como fluem em certas atividades. Pacheco (2015) aponta isso em seu livro, quando explica algum dos funcionamentos da Escola da Ponte:

A elaboração do plano torna-se fundamental para a organização da Ponte, pois os alunos chegam pela manhã nos espaços de trabalho e já sabem que precisam elaborar o seu plano do dia (...) No final de cada quinzena acontece uma autoavaliação, na qual os alunos podem registrar os objetivos alcançados, aquilo que gostariam de fazer ou mesmo aquilo que sentirão dificuldade. A auto-avaliação é, realmente uma prática constante da escola. Ao final de cada dia, as crianças fazem a avaliação do que foi feito, o que estabelece maior coerência: planejou, avaliou. Para todo "planejo do dia" acontece uma auto-avaliação, para que elas tenham a dimensão 
das intenções cumpridas, ou não (...) É justamente por ser uma atividade complexa que a auto-avaliação precisa ser praticada constantemente (...) É uma prática cotidiana, que ensina a necessidade da reflexão no processo de construção do conhecimento (p.21; p. 32, 33).

Como dito, a escrita reflexiva é uma prática utilizada amplamente pelas ENT, inclusive como ferramenta avaliativa em alguns casos, como destacado por Pacheco no fragmento acima.

Nas últimas falas dessa categoria IV, podemos observar três pontos primordiais. O primeiro é a questão dos exercícios de roda e/ou grupo tão presentes nas ENT. Essa prática de desenvolver-se no coletivo é uma característica muito presente nestas escolas e, através das falas, tanto das educadoras quanto dos alunos, podemos observar a importância dessas práticas para o currículo das ENT. As práticas de trabalhos em grupos auxiliam os sujeitos ali imersos a desenvolverem as demais práticas trabalhadas acima, reforçando principalmente a questão do olhar para si através do outro. Ademais, observamos a questão da auto-gestão do tempo como uma nova ferramenta de autoconhecimento, aplicada também de forma ampla não só nas ENT aqui citadas, como em outras ENT como a Escola da Ponte. Por fim, notamos a escrita reflexiva como uma possibilidade de aprendizagem no sentido da auto-gestão. Uma vez que, a escrita reflexiva além de nos auxiliar a conhecer nossos sentimentos, anseios e demais estados emocionais, ela também nos proporciona compreender melhor como ocorre o nosso processo de aprendizagem, compreendendo assim limitações, facilidades e questões de temporalidade nos processos educativos.

\section{Conclusões}

Para concluirmos então observamos que, no decorrer da elaboração deste artigo foi possível perceber uma série de ferramentas e exercícios utilizados pelas ENT em seus currículos para promover o autoconhecimento dos sujeitos. Neste trabalho, apontamos através dos quatro vídeos como essas escolas vão explorando estas ferramentas e como os sujeitos professores, alunos, pais e demais comunidade escolar - ali imersos vão acessando estes processos e construindo assim a suas subjetividades.

As ferramentas foram divididas em quatro grande categorias que denominamos de (I) O exercício de Conhecer-se; (II) A Escuta Ativa e o Silêncio; (III) As Assembléias e (IV) os Exercícios de Roda e Escrita Reflexiva. Destacamos, no desenvolver do artigo, que estas categorias se intercomunicam e buscam projetar nos sujeitos estímulos que promovam o exercício de olhar para si. As ENT trabalham a questão do autoconhecimento, também denominado de educação emocional entre outras nomenclaturas na literatura. Assim, neste 
trabalho apontamos nas quatro categorias algumas das ferramentas que as ENT utilizam para promover essa educação emocional dentro de seus currículos. Ressalvamos, também, que essas ferramentas são oriundas de diferentes campos de saberes, sendo recorrente o cruzamento do campo da educação com o da psicologia e da saúde, como notamos através das referências utilizadas para a elaboração desse trabalho.

Como reflexões finais destacamos como a educação emocional aparece dentro das escolas ainda que de forma tímida e marginalizada, sendo associada quase que exclusivamente com a questão da resolução de conflitos. Em contrapartida, as ENT parecem trazer um movimento contrário a isso, uma vez que, seus currículos são pautados majoritariamente em buscar um equilíbrio do ser de forma integral, incluindo assim, questões equilíbrio mental em suas práticas pedagógicas.

Por fim, observamos também que esse currículo "diferenciado" das ENT produz novas formas de subjetividade. Os vídeos, através de suas imagens e falas, nos permitem observar a forma como esses sujeitos se colocam perante diferentes situações. Evidentemente, os sujeitos - alunos, alunas, professores e pais - desenvolvem dentro de si um senso de autoconhecimento, desenvolvendo assim clareza sobre o que sentem e como lidar com suas próprias emoções. Além disso, é evidente, principalmente nas falas, a forma como os alunos e alunas se colocam e se expressam entre si e perante a sociedade. Essas posturas são implicações derivadas do currículo das ENT, uma vez que, pensar o currículo é pensar o sujeito quem desejamos formar. Assim, na nossa compreensão, as ENT dirigem suas práticas curriculares para tentarem desenvolver o tão aclamado cidadão crítico, criativo e participativo presente nas pesquisas educacionais e na própria Lei de Diretrizes e bases da Educação Nacional (BRASIL, 1996).

Finalizando, notamos que o autoconhecimento dentro das escolas parece não ser uma temática recorrente dentro das pesquisas acadêmicas. Compreendemos que, devido a nomenclatura ser vasta, existe uma dispersão de material no sentido de muitas vezes diferentes autores abordarem as mesmas questões, porém as nomearem de formas diferentes. Mesmo assim, salientamos a importância deste trabalho dentro do contexto acadêmico já que este artigo, além de trazer ao debate a questão do autoconhecimento no currículo das ENT, aborda também outra temática pouco explorada na literatura que são as próprias ENT. Assim, este trabalho convida os/as leitores/leitoras a explorarem e conhecerem mais dessa temática, abrindo assim um caminho para o debate sobre as ENT dentro dos ambientes acadêmicos. 


\section{Referências}

BALDIN; N. ; MUNHOZ, E. Snowball (bola de neve): uma técnica metodológica para pesquisa em educação ambiental comunitária. In: X Congresso Nacional em Educação Educere. Curitiba, 2011. Anais ISSN: 2176-1396. Curitiba/ Paraná, 2011. Disponível em: http://educere.bruc.com.br/CD2011/pdf/4398_2342.pdf.

BARRERA, T. O movimento brasileiro de renovação educacional no início do século XXI. 2016. 274 f. Tese (Doutorado em Educação) - Programa de Pós-Graduação em Educação da Faculdade de Educação da USP, Universidade de São Paulo, São Paulo.2016.

Canal Futura. Destino: Educação - Escolas Inovadoras | La Cecilia (Argentina). Disponível em: https://www.youtube.com/watch?v=Z4qk6lklwTU\&t=25s. Acessado em: 01 de out.2017.

Autoras. Um estudo acerca das escolas não-tradicionais: como o discurso das mídias produzem estas escolas? In: SEMINÁRIO BRASILEIRO DE ESTUDOS CULTURAIS E EDUCAÇÃO / SEMINÁRIO INTERNACIONAL DE ESTUDOS CULTURAIS E EDUCAÇÃO, 7,4, 2017, Canoas. Anais ISSN: 2446-810X. Canoas/Rio Grande do Sul:Editora da Ulbra, 2017. ${ }^{\mathrm{a}}$

Destino: educação - escolas inovadoras um olhar sobre o currículo das escolas inovadoras apresentadas pelo canal Futura In: SEMINÁRIO BRASILEIRO DE ESTUDOS CULTURAIS E EDUCAÇÃO / SEMINÁRIO INTERNACIONAL DE ESTUDOS CULTURAIS E EDUCAÇÃO, 7,4, 2017, Canoas. Anais ISSN: 2446-810X. Canoas/Rio Grande do Sul:Editora da Ulbra, 2017. ${ }^{\mathrm{b}}$

FOUCAULT, M. Vigiar e Punir: nascimento da prissão. Petrópolis: Editora Vozes, 2014.301p.

KÜNZLE, M. R. Escolas alternativas em curitiba: trincheiras, utopias e resistências pedagógicas (1965 - 1986). 2011. 215 f. Tese (Doutorado em Educação) - Pós-Graduação em Educação, Universidade do Paraná, Curitiba, 2011.

Mapeamento Coletivo de Educação Alternativa (REEVO). Disponível em: http://map.reevo.org/?l=pt_PT. Acessado em: 13 out. 2017.

MESQUITA, A. C.; CARVALHO, E. C. A Escuta Terapêutica como estratégia de intervenção em saúde: uma revisão integrativa. Revista da Escola de Enfermagem da USP, v.48, n.6, p. 1127 - 1136, ISSN 0080-6234. Disponível em:

http://www.scielo.br/pdf/reeusp/v48n6/pt_0080-6234-reeusp-48-06-1127.pdf. Acessado em: 23 nov. 2017.

PACHECO, J. ; PACHECO, M. F. Escola da ponte - uma escola pública em debate. São Paulo: Cortez, 2015. 208 p.

PARAÍSO, M.A. Currículo, Desejo e Experiência. Revista Educação e Realidade, v.34, n.2, p.277-293,2009. ISSN 2175-6236. Disponível em:

http://seer.ufrgs.br/index.php/educacaoerealidade/article/view/9355/5545. Acessado em: 12 out.2017.

PARAÍSO, M. A. Currículo nômade: quando os devires fazem a diferença proliferar. In: KIRCHOF, E. R. ; WORTMANN, M. L.; COSTA, M. V. (Org.). Estudos Culturais e 
Educação Contingências, articulações, aventuras, dispersões. Canos: Editora da ULBRA, 2015, p. 269-288.

RÊGO, C. C. A. B; ROCHA, N. M. F. Avaliando a educação emocional: subsídios para um repensar da sala de aula. Ensaio: Avaliação e Políticas Públicas em Educação, v.17, n.62, p.135-152, jan./mar. 2009. ISSN 1809-4465. Disponível em:

http://www.scielo.br/pdf/ensaio/v17n62/a07v1762.pdf. Acessado em: 17 nov. 2017.

ROCHA, M. D.; FLORES, J. F; MARQUES, L. F. Fundamentos da meditação no ensino básico: transdisciplinaridade, holística e educação integral. Revista Terceiro Incluído Transdisciplinariedade e Educação Ambiental, v.5, n.2, p.398-413, jul/dez. 2015. ISSN: 2237-079X. Disponível em: https://www.revistas.ufg.br/teri/article/viewFile/38797/19569. Acessado em: 20 nov. 2017.

[Re]Considere. O que eles têm para nos dizer? - Episódio 1 - Escuela Democrática de Huamachuco (Peru). Disponível em: https://www.youtube.com/watch?v=zOcmU9kv0ms. Acessado em: 01 de out.2017.

. O que eles têm para nos dizer? - Episódio 2 - Tierra Fértil (Argentina). Disponível em: https://www.youtube.com/watch?v=Z7zJNPoTkpI\&t=403s. Acessado em: $01 \mathrm{de}$ out.2017.

. O que eles têm para nos dizer? - Episódio 3 - La Cecilia (Argentina). Disponível em: https://www.youtube.com/watch?v=vZ0LBOGxz4w. Acessado em: 01 de out.2017.

ROSENBERG, M. B. Comunicação não-violenta: técnicas para aprimorar relacionamentos pessoais e profissionais.São Paulo: Ágora,2006. 285p.

SILVA, T.T. Documentos de Identidade. Belo Horizonte: Autêntica Editora, 2015. 154p.

TAMBERLINI, A. R. M. B. Ensino Vocacional: formação integral, cultura e integração com a comunidade em escolas estaduais paulistas na década de 1960. Revista HISTEDBR On-line, v.16, n.70, p.119 - 137, dez. 2016. ISSN: 1676-2584. Disponível em:

https://periodicos.sbu.unicamp.br/ojs/index.php/histedbr/article/view/8649211. Acessado em: 17 nov. 2017.

VELASCO, H. M. ; DE RADA, A. D. La lógica de la investigación etnográfica. Un modelo de trabajo para etnógrafos de la escuela. Madrid: Trotta, 2004, 303p. 